Fecha de recepción: 20 de agosto de 2020

Fecha de evaluación: 11 de diciembre de 2020 Fecha de aprobación: 16 de diciembre de 2020

\section{Reflexiones acerca de la implementación del Acuerdo de paz que afectan al campesino y al reinsertado*}

Edwoin Sergio Trujillo Florián** Miryam Edith Barón Colmenares** María Margarita Tirado Álvarez ${ }^{* * *}$
Para citar este artículo

Trujillo, E., Barón, M. \& Tirado, M. (2021). Reflexiones acerca de la implementación del acuerdo de paz que afectan al campesino y al reinsertado. Vía luris, 30, 73-92. https://doi. org/10.37511/viaiuris.n30a3

\title{
RESUMEN
}

La reconciliación ha sido un reto para el posconflicto colombiano, en medio de la dificultad de construir una identidad nacional que se refleja en la polarización política que se vive. La historia permite establecer víctimas y victimarios, sin embargo, definir el camino hacia la reconciliación conlleva un desafío; debe estar inmersa la fuerza para perdonar y olvidar, y los victimarios deben admitir sus actos. ¿Qué factores impiden elaborar un marco de justicia en el proceso de recordación, olvido y reconocimiento de las acciones criminales pasadas y que se siguen presentando que no permiten que se lleve a cabo la implementación del acuerdo de paz celebrado entre el Gobierno Nacional y las Farc-EP? El objetivo es determinar los problemas sociales, económicos y de orden público de los campesinos y los reinsertados como víctimas, a partir de un enfoque de justicia en el marco del posconflicto. Se proponen, entonces, algunas líneas de pensamiento mediante la investigación documental interpretativa y el proceso reflexivo está dado en el análisis de los documentos revisados. Como conclusión principal se propone que es necesario un proceso de reconciliación nacional que involucre a los detractores del acuerdo de paz para identificar los factores que impiden la paz en los campos de Colombia.

* Artículo de reflexión del Grupo de Investigación «Red de Estudios Sociojurídicos Comparados y Políticas Públicas -RESCYPP» de la Universidad Militar Nueva Granada y del grupo «Derecho penal contemporáneo» de la Universidad La Gran Colombia. Periodo 2020. Bogotá, Colombia.

** Abogado especialista en Derecho Procesal Penal y Doctor en Bioética, Magíster. Docente-investigador. «Red de Estudios Sociojurídicos Comparados y Políticas Públicas -RESCYPP», Facultad de Derecho, Universidad Militar Nueva Granada. Bogotá, Colombia. Correo electrónico: edwin.trujillo@unimilitar.edu.co. ORCID ID: https://orcid. org/0000-0003-2203-7704.

*** Doctoranda en Gerencia Pública y Política social Universidad de Baja California (México), Magister en Docencia.Abogada, psicóloga. Docente-investigadora «Red de Estudios Sociojurídicos Comparados y Políticas Públicas -RESCYPP», Facultad de Derecho, UniversidadMilitar Nueva Granada. Bogotá, Colombia.Correo electrónico: miryam. baron@unimilitar.edu.co ORCID ID: https://orcid.org/0000-00028454-697X

**** Doctoranda en Derecho por la Universidad de Buenos Aires (Argentina), Magister en Ciencias Penales y Criminológicas, especialista y abogada. Docente-investigadora «Red de Estudios Sociojurídicos Comparados y Políticas Públicas -RESCYPP», Facultad de Derecho, Universidad Militar Nueva Granada. Correo electrónico: maria.tirado@ unimilitar.edu.co ORCID ID https://orcid.org/0000-0002-6947-981X. Bogotá, Colombia.
DOI: https://doi.org/10.37511/viaiuris.n30a3

Creative Commons Atribución-NoComercial-Compartirlgual 4.0 Internacional (CC BY-NC-SA 4.0).

\section{(c) (7) (8)}

\section{Palabras clave}

Política, totalitarismo, clase campesina, justicia, memoria colectiva, paz. 


\title{
Reflections on implementation of the peace agreement that affects the farmer and the reinserted
}

\author{
Edwoin Sergio Trujillo Florián \\ Miryam Edith Barón Colmenares \\ María Margarita Tirado Álvarez.
}

\begin{abstract}
Reconciliation has been a challenge for the Colombian post-conflict, the difficulty of building a national identity is reflected in the political polarization that exists. History makes it possible to establish victims and perpetrators, however, defining the path to reconciliation involves a challenge; the force to forgive and forget must be immersed and the perpetrators must admit their actions. What factors prevent the development of a framework of justice in the process of remembrance, forgetfulness and recognition of past criminal actions and that continue to occur that do not allow the implementation of the peace agreement between the National Government and the Farc-EP? The objective is to determine the social, public order and economic problems of peasants and those reinserted as victims from a Justice approach in the post-conflict framework. Some lines of thought are proposed through interpretative documentary research and the reflective process is reflected in the documents analyzed. As a main conclusion, it is proposed that a national reconciliation process that involves the detractors of the peace agreement is necessary to identify the factors that prevent peace in the fields of Colombia.
\end{abstract}

\section{Keywords}




\title{
Reflexões sobre a implementação do acordo de paz que afetam o camponês e a pessoa reintegrada
}

\author{
Edwin Sergio Trujillo Florián \\ Miryam Edith Barón Colmenares \\ María Margarita Tirado Álvarez
}

\section{RESUMO}

A reconciliação tem sido um desafio para o pós-conflito colombiano, a dificuldade de construir uma identidade nacional se reflete na polarização política que se vive. A história permite estabelecer vítimas e vitimizadores, no entanto, definir o caminho para a reconciliação implica um desafio; a força para perdoar e esquecer deve ser imersa e os vitimizadores devem admitir seus atos. A questão é: Que fatores impedem a elaboração de uma estrutura de justiça no processo de lembrar, esquecer e reconhecer ações criminais passadas e que continuam a ocorrer que não permitem a implementação do acordo de paz entre o Governo Nacional e o EP das Farc? O objetivo é determinar os problemas sociais, de ordem pública e econômicos dos camponeses e os reintegrados como vítimas de uma abordagem de Justiça no quadro pós-conflito. Algumas linhas de pensamento são propostas através de pesquisas documentais interpretativas e o processo de reflexão é refletido nos documentos analisados. Como conclusão principal é proposto que um processo de reconciliação nacional envolvendo os detratores do acordo de paz é necessário para identificar os fatores que impedem a paz no campo colombiano.

Palavras-chave

Política, totalitarismo, classe camponesa, justiça, memória coletiva, paz. 


\title{
Réflexions sur la mise en \\ oeuvre de l'accord de paix qui affectent le paysan et la personne réinsérée
}

\author{
Edwoin Sergio Trujillo Florián \\ Miryam Edith Barón Colmenares \\ María Margarita Tirado Álvarez.
}

\section{RÉSUMÉ}

La réconciliation a été un défi pour la Colombie post-conflit, la difficulté de construire une identité nationale se reflète dans la polarisation politique vécue. L'histoire permet d'établir des victimes et des bourreaux, mais définir la voie de la réconciliation représente un défi ; il faut trouver la force de pardonner et d'oublier et les bourreaux doivent reconnaître leurs actes. La question est la suivante : quels sont les facteurs qui empêchent l'élaboration d'un cadre de justice dans le processus de mémoire, d'oubli et de reconnaissance des actions criminelles passées et qui continuent à se produire qui ne permettent pas la mise en œuvre de l'accord de paix entre le gouvernement national et le PE des Farc ? L'objectif est de déterminer les problèmes sociaux, d'ordre public et économiques des paysans et des réinsérés comme victimes à partir d'une approche de Justice dans le cadre post-conflit. Des pistes de réflexion sont proposées à travers une recherche documentaire interprétative et la démarche réflexive se reflète dans les documents analysés. En guise de conclusion principale, il est proposé qu'un processus de réconciliation nationale impliquant les détracteurs de l'accord de paix soit nécessaire pour identifier les facteurs qui empêchent la paix dans la campagne colombienne.

Mots-clés

Politique, totalitarisme, classe paysanne, justice, mémoire collective, paix. 


\section{INTRODUCCIÓN}

El gran reto del Estado colombiano después de décadas de enfrentamiento con el grupo Farc-EP era lograr un acuerdo de paz y lo consiguió. Sin embargo, las dificultades al construir una identidad nacional se reflejan en la polarización política como factor de intolerancia. Por ejemplo, encontrar a la víctima con el victimario conlleva un desafío para la reconciliación, lo que lleva a preguntarse: ¿Qué factores impiden elaborar un marco de justicia en el proceso de recordación, olvido y reconocimiento de las acciones criminales pasadas y que se siguen presentando que no permiten que se lleve a cabo la implementación del acuerdo de paz celebrado entre el Gobierno Nacional y las Farc-EP?

El objetivo principal del presente artículo es determinar los problemas sociales, económicos y de orden público de los campesinos y los reinsertados como víctimas, a partir de un enfoque de justicia en el marco del posconflicto.

Como primer objetivo específico se pretende describir la problemática existente en la repartición de las tierras para los campesinos como víctimas del conflicto armado, los modelos normativos que se han querido implementar y las dificultades encontradas en razón a los discursos totalitaristas que se aprovechan de la ineficiencia del Estado para llegar al campo colombiano, y que de paso influyen en la legislación colombiana, por ejemplo, el proyecto de reforma a la Ley 1448 de 2011.

El segundo objetivo específico se centra en definir el totalitarismo y la polarización como factores que inciden en el pensamiento colectivo de un país que tiene serias dificultades para discernir lo justo (justicia como principio). Para ello se hace un breve recorrido por la historia del conflicto armado y las dictaduras invisibles en Colombia, las cuales han influido en la difícil implementación de los acuerdos.

Un tercer objetivo busca establecer, por medio de la reflexión, la importancia de la memoria histórica desde la visión filosófica de Walter Benjamin (2003), lo cual puede repercutir en la construcción de una verdadera comisión de la verdad en pro de una justicia que, al ser transicional, permita el reencuentro entre las partes involucradas.

Las Farc-EP encontró una salida política con el gobierno de Juan Manuel Santos. Después de la firma del Acuerdo Final para la Terminación del Conflicto y la Construcción de una Paz Estable y Duradera (en adelante, el Acuerdo), la debacle ocurrió el 2 de octubre de 2016, cuando en consulta popular a través de plebiscito ganó el 'NO' a la ratificación de lo acordado, lo que significó un replanteamiento de algunos puntos del documento. Este evento dio pie al nacimiento de grupos partidarios y detractores: por una parte, el Gobierno Nacional y, por otra, la oposición.

La principal estrategia empleada por la oposición fue la utilización de los medios masivos de comunicación, que buscaba generar en la conciencia colectiva una animadversión hacia la Jurisdicción Especial para la Paz (JEP). Este singular aspecto trasciende hoy, a más de tres años de aquel acontecimiento, que de cierto modo dejó maltrecha la democracia en Colombia.

Uno de los mayores retos que enfrentan países que intentan salir de situaciones de conflicto armado interno es lograr un equilibrio entre los acuerdos para establecer la paz, la restauración de la justicia y la reconciliación. Pero no existe una receta única para lograrlo; los procesos de justicia y reconciliación están bajo la influencia de incontables componentes entre los que se hallan el impacto del conflicto, los términos de su resolución, los recursos disponibles, el nivel de voluntad política de consenso existente, la capacidad institucional, las normas culturales, entre otros. Meltzer (2004) considera que en Colombia hablar de justicia es hablar de impunidad, especialmente cuando no hay credibilidad en la justicia ordinaria.

Un importante eje en la implementación y consolidación de los acuerdos es la existencia de planes y programas dentro de una política pública que tenga todo el respaldo político. Aunque la reconciliación también es de vital importancia, en situaciones de posconflicto esta "no implica un estado de unión, amistad o armonía en las relaciones. El propósito es generalmente menos ambicioso" (Govier, citado en Barreto, 2017, p. 156). El objetivo es más bien "la construcción y sostenimiento de relaciones con suficiente cercanía y confianza para gestionar los conflictos y problemas que inevitablemente emergerán en el tiempo" (Barreto, 2017, p. 185).

En Colombia son numerosos los obstáculos asociados a la reconciliación, sin embargo, siempre 
que exista voluntad política hay posibilidades de paz estable y duradera, aunque en verdad aquella tiene un papel protagónico en su consecución. La implementación del proceso de paz en Colombia ha presentado múltiples dificultades que han impedido llevar a cabo los puntos acordados hace más de tres años. Los problemas sociales, políticos, económicos y de orden público retrasan el proceso de reconciliación nacional e inciden en el surgimiento de nuevas fuerzas que buscan desestabilizar el proyecto que han trazado las partes para lograr el fin de un conflicto que duró más de medio siglo.

El panorama no es alentador. En lugar de hablar de posconflicto, o incluso de posacuerdo, disidentes y partidos opositores pretenden volver a conceptos como la revictimización de los sujetos que han sufrido en mayor medida las consecuencias derivadas de la guerra: los campesinos y los guerrilleros reinsertados.

Para lograr el objetivo principal de este documento se describen los problemas surgidos en la democracia colombiana, entre los cuales se encuentran dos aspectos íntimamente ligados: de un lado está la polarización política, la cual genera fisuras que no permiten el acercamiento entre las partes, y de otro lado está el asesinato de líderes sociales, que redunda en la imposibilidad de garantizar de manera real y efectiva la participación política para los campesinos y los reinsertados voluntariamente sometidos a un proceso de paz, quienes hacen actividades de liderazgo en la comunidad. Todo esto está enmarcado en un país dominado por el miedo histórico.

En este sentido, se ahonda en los problemas estructurales del campo colombiano debido a la ausencia de una reforma agraria, los cuales son aprovechados actualmente por los grupos armados y delincuenciales organizados. Estos han tomado ventaja del vacío dejado por las Farc-EP en algunas zonas del país para tener el control militar y agrícola con el cultivo de plantaciones para uso ilícito y labores de minería ilegal, hechos que desencadenan en una notable deforestación. Bajo este escenario, el conflicto social se agrava y asienta en forma permanente, al involucrar nuevos actores armados con poderío militar y económico que les permiten avanzar por la senda del autoritarismo, de la mano de grupos políticos de derecha.

\section{METODOLOGÍA}

El presente artículo es resultado de una investigación documental e interpretativa propia. Es teórica, de base cualitativa y con enfoque hermenéutico crítico. La base del proceso reflexivo se sustenta en la información obtenida y analizada mediante la consulta bibliográfica de textos y artículos de revistas indexadas de contenido jurídico y ius filosófico, análisis de registros, normativas y proyectos regulatorios sobre el tema, además de doctrina y reflexiones judiciales, que sustentan un enfoque aplicable en términos de justicia, con análisis crítico del discurso, para responder a la pregunta de investigación, lo que hace necesario determinar los problemas sociales, económicos y de orden público de los reinsertados y los campesinos para el acceso a la justicia. A fin de cumplir este objetivo se deben describir las dificultades que se han evidenciado para lograr la verdad, justicia, reparación y no repetición, como presupuestos de una paz estable y duradera.

Es de señalar que el diseño elegido no revistió dificultades ni limitaciones en su labor de medir las implicaciones prácticas del proyecto; sin embargo, la discusión encontró aristas diversas, polarizadas y divididas en la exposición de los contenidos consultados (Gómez, García, Arango \& Medrano, 2020; Gonzáles \& Estrada, 2019; Ruiz, 2020) -lo que es de esperarse dado el abordaje científico-jurídico de un tema sensible como el que trata este texto-, las cuales fueron debidamente revisadas en aras de mostrar, en lo posible, un panorama integral del problema.

A continuación, se hace referencia a los más importantes puntos que impiden la implementación de los acuerdos, partiendo de una descripción del terror y del terrorismo acaecido en Colombia, base sobre la cual se puede representar la imposibilidad de reconciliación en la era del posconflicto.

\section{RESULTADOS}

\section{La historia del terror como fuente de poder en Colombia}

Para abrir un espacio a reflexiones posteriores, es necesario enunciar un fenómeno invisible en las urbes, esto es, el gamonalismo, cuyos discursos totalitaristas inciden en las consecuencias negativas 
para revictimizar a quienes desean el derecho humano a la paz.

Ahora bien, cuando se trata de justicia transicional, se evidencian dos necesidades: por un lado, la justicia y, por el otro, el derecho a la paz, el cual ha sido precedido, lo cual es un contrasentido de la guerra. En la consecución del derecho a la paz posiblemente la talanquera más representativa es la apología del terror.

Un problema social es el totalitarismo, el cual se encuentra detrás de la ideología de terror individual, pero que mayoritariamente es colectivo, y por eso llega a convertirse en un terrorismo de Estado. El concepto de terrorismo en el posconflicto está siendo manipulado e instrumentalizado con varias finalidades, entre las que se destacan la limitación a los derechos humanos de quienes no estén de acuerdo con el sistema o con el Gobierno.

El terrorismo estatal sin medida ha sido destinado a la eliminación política de movimientos populares, a las amenazas y al asesinato de líderes sociales y de aquellos que de algún modo disientan de la política gubernamental; aun así, el discurso estatal va dirigido a la defensa de la democracia. Es muy frecuente la utilización estratégica de este concepto, aunque se ha dicho que adquiere un matiz especial cuando a los gobiernos terroristas de Estado, en aras de defender el Estado mismo, no les importa que sus acciones vayan en parte acompañadas de actos de terrorismo dirigidos contra "ciudadanos inermes $y$, por lo tanto, queda en el ostracismo la locución democracia en su sentido estricto" (Torres, 2010, p. 141).

Bajo esa óptica del terrorismo estatal, los gamonales han sido históricamente los sembradores de la violencia en el campo colombiano, bien sea por ser los usurpadores de la tierra o bien por financiar campañas políticas para anquilosar en el poder a grandes latifundistas. El gamonalismo es un fenómeno que ha incidido en el poder durante las últimas décadas y todavía pretende hacerlo por medio de sus representantes en el Congreso a través de proyectos de ley, iniciativas legales o mediante mensajes de desesperanza dirigidos a quienes le han apostado volver al campo, reintegrarse a la vida civil y ejercer una activa participación democrática. En este sentido, el ambiente polarizador y totalitario se debe a los gamonales o caciques políticos que todavía rondan en el escenario de lo público.
Estos aspectos no son tan prometedores, ya que pese a las expectativas del Acuerdo, hasta ahora no hay sustitución de cultivos ilícitos, reforma agraria integral, mejora o ampliación de la participación en política ni una modificación del sistema de justicia, lo que no permite vislumbrar un futuro en armonía, con reconciliación y en paz. Al contrario, la guerra, el miedo y el terrorismo desde el Estado han permanecido latentes.

Durante largo tiempo, el terror estatal por medio de los gamonales del campo ha empoderado ciertos sectores de la política colombiana. Prueba de ello son los hechos ocurridos a finales de los años 80 y principios de los 90, cuando se presentó el genocidio del partido político Unión Patriótica (UP), un hecho criminal que no fue trascendental para la gran colectividad nacional y pasó desapercibido en su momento.

\section{RESULTADOS Y DISCUSIÓN}

\section{Primera reflexión: sin acceso a la tierra para el campesino}

Este apartado describe el problema generado en la repartición de la tierra para los campesinos víctimas del conflicto. La distribución de la tierra es fundamental para las trasformaciones sociales, económicas y políticas en Colombia, no de otra manera se explica que un acuerdo de paz con el grupo insurgente más representativo del momento comience con la inclusión de una reforma rural integral, cuyo costo es el más alto entre los diversos puntos del documento, calculado en 110,6 billones de pesos (Departamento Nacional de Planeación [DNP], 2017).

Si bien es cierto que se han dado pasos para avanzar en los propósitos señalados en tal reforma rural, como la creación del Fondo de Tierras y del Registro de Sujetos de Ordenamiento (RESO), la carencia de tierra para los campesinos sigue siendo una realidad, pues aún no se verifica la entrega o titulación de una cantidad significativa de hectáreas. Ya desde los primeros informes de seguimiento se insistía en la necesidad de contar con acciones contundentes en la materia, tales como "priorizar la asignación de recursos y esfuerzos de la Agencia Nacional de Tierras (ANT) destinados a la ejecución del Procedimiento Único de Ordenamiento Social de la Propiedad Rural a sufragar los gastos de formalización 
y titulación de los pequeños productores" (Instituto Kroc de Estudios Internacionales de Paz, 2017, p. 14).

Estas son algunas de las cifras a noviembre de 2018:

- Al fondo de tierras ingresaron 3.638 predios, que corresponden a 500.000 hectáreas. Estas tierras se entregaron a habitantes de 138 municipios en 26 departamentos.

- Se legalizaron un millón y medio de hectáreas, es decir el 22 por ciento de la meta de 7 millones de hectáreas.

- Se creó una ley que acelera la extinción de dominio y se adjudicaron 16.582 baldíos. (Semana Rural, 2018)

Por otra parte, la garantía de verdad, justicia, reparación y no repetición es una tarea que, según Rendón (2003), llevará muchos años, porque lo importante es quitarle el ritmo a la violencia, por medio de las comisiones de la verdad. El gran componente de violencia lo tiene la lucha por la tierra, su despojo y el desplazamiento forzado que se ha originado a raíz de esas prácticas criminales perpetradas por grupos de guerrillas, paramilitares y agentes del Estado.

Como consecuencia del Acuerdo de paz, la reforma agraria está llamada a servir como solución de los problemas del campesinado colombiano; sin embargo, y a pesar de esa declaración, ya se habían advertido las dificultades que se podrían generar con la ausencia de una verdadera reforma agraria que permitiera el acceso a una justicia igualitaria en términos económicos, sociales y de paz en sus lugares para los campesinos colombianos. Tales llamados de atención se enumeran así:

1. La distribución de la propiedad de la tierra.

2. La importación de productos agropecuarios.

3. El procesamiento de productos agropecuarios.

4. La comercialización y precios de sustentación.

5. El crédito subsidiado y de fomento.

6. La planeación económica en el sector.

7. El asunto de los cultivos ilegales.
8. La destrucción de los ecosistemas y el medio ambiente.

9. La propiedad de la tierra en zonas petroleras o de megaproyectos.

10. Los derechos de los pueblos indígenas.

11. Las tierras de las comunidades negras.

12. El desplazamiento de poblaciones por la violencia. (Mondragón, 2002, p. 59).

En ese escenario, los grupos armados ilegales y las Ilamadas disidencias (aquellos no sometidos al Acuerdo) han querido aprovechar la ineficiencia del Estado y la institucionalidad a fin de recuperar el terreno dejado por las Farc-EP. Desde un principio se advirtió que las 23 zonas veredales de concentración para el agrupamiento de los excombatientes de la guerrilla podrían presentar inconvenientes de diversa índole como el clima, la ubicación geográfica, la dificultad de acceso y el arriendo de predios con los habitantes de la zona. Lo que no se avizoró fue la retoma por parte de los demás grupos armados mediante actos de violencia hacia los líderes de estas zonas, situación compleja que afecta un proceso que pretende culminar más de medio siglo de conflicto armado.

Das (1997) afirma que el sufrimiento social es el conjunto de problemas humanos que tienen su origen en las heridas del pasado; por lo tanto, se entiende que en el contexto de un posconflicto se está llegando al fenómeno de la normalización de la violencia, porque ya existen unas heridas abiertas por la guerra que difícilmente se podrán cerrar con el asesinato de los líderes sociales, quienes son las personas encargadas de ser voceras tanto de los reinsertados como de los habitantes del campo para la llegada de políticas públicas de inversión y reforma agraria.. Esa normalización, que en últimas se convierte en indiferencia, es aprovechada por estos grupos que semanalmente acaban con la vida de hasta tres personas.

Un ejemplo del discurso totalitario por parte de los llamados gamonales se puede evidenciar en el proyecto de reforma a la Ley 1448 de 2011. Es preciso explicar que el propósito inicial de esta norma corresponde a la devolución de las tierras a los campesinos que habían sido sacados de sus tierras. Así, en beneficio de las víctimas se estipuló 
una sola instancia y se invirtió la carga de la prueba, es decir, el ocupante no puede apelar la sentencia y la víctima no tiene la carga de probar el despojo, pero si el ocupante demuestra buena fe, puede ser indemnizado.

El proyecto de Ley 131 de 2018, que pretende reformar la descrita Ley 1448, busca garantizar los derechos de los segundos ocupantes Ilamándolos "poseedores de buena fe" y haciéndolos pasar por víctimas. El rechazo por parte de los movimientos sociales campesinos e indígenas, partidos políticos y congresistas frente a esta iniciativa no se ha hecho esperar y las críticas son diversas, entre las cuales se encuentran: la desnaturalización de los derechos fundamentales a la restitución de las tierras; la limitación de la titularidad del derecho porque el campesino quedaría desprotegido al carecer de recursos económicos y logísticos para demostrar situaciones como que la ocupación fue "viciada, clandestina o violenta"; la justificación de la venta forzada como una categoría distinta al despojo; el desmonte de la carga de la prueba; el establecimiento de medidas de persecución para líderes y organizaciones sociales, y el hecho de que no aborda su prórroga, ya que su periodo de vigencia termina el 10 de junio de $2021^{1}$.

Es necesario afirmar que Ley 1448 de 2011 ha representado un gran esfuerzo para solucionar el despojo de tierras a los campesinos en Colombia, la mayoría en condición de pobreza, con niveles bajos de escolaridad y sin la posibilidad de acceder a la justicia, situación que fue aprovechada en el pasado por los grupos paramilitares, los narcotraficantes $y$ las guerrillas para ganar terreno, y que en el presente desean recuperar.

Por ello, el proceso de única instancia y la inversión de la carga de la prueba para el despojador u ocupante ilegal es la medida efectiva para que las víctimas accedan a la justicia, pues si un proceso ordinario en una ciudad y entre personas con poder adquisitivo puede durar años y hasta décadas, no es difícil imaginar lo complejo que será para un campesino de escasos recursos demostrar un derecho

1 Las críticas al proyecto de Ley 131 de 2018 se encuentran en un comunicado a la opinión pública, al Congreso de la República y al Gobierno Nacional, del 23 de octubre de 2018, y se puede consultar en: https://viva.org.co/2-uncategorised/651rechazo-a-la-reforma-de-la-ley-1448-de-2011. Consultado el 11 de mayo de 2020. en una zona apartada con un proceso judicial en condición de desventaja.

Cabe traer a colación el análisis de Patricia Jaramillo (2006) sobre la pobreza en Colombia, muy unido al asunto del que se viene hablando:

Desde la óptica del desarrollo rural y la seguridad alimentaria, la pobreza se circunscribe en un espacio en donde su superación debe ir acompañada de políticas y acciones precisas que tomen en cuenta la complejidad del problema y las condiciones del país, y que identifiquen las relaciones campo-ciudad como determinante para combatir la pobreza en toda su dimensionalidad. (p. 51).

En materia de desarrollo rural y sustitución de cultivos, hay que indicar que desde inicios de este siglo y sin existir cambios trascendentales, han sido varios los programas rurales y las diversas acciones gestadas en contra de la pobreza, las cuales esbozaron "un mejoramiento de las condiciones de vida de los habitantes del campo y del país en general, con logros como aumento en la esperanza de vida y reducción de la mortalidad infantil" (Jaramillo, 2006, p. 52).

Es claro que el problema agrario se ha recrudecido, hecho que ha llevado a que los cultivos de coca hayan aumentado de forma progresiva desde 2013: para el año 2018, el crecimiento fue del $17 \%$ con relación a 2016 y 2017. Se tiene que el 64 \% del incremento se sitúa en Antioquia, Cauca, Putumayo y Norte de Santander. De los 17 proyectos productivos aprobados, solo dos han recibido el desembolso, es decir, se ha beneficiado menos del $1 \%$ de los 13.049 reinsertados. Para diciembre de 2018 ya iban 81 excombatientes y 21 familiares asesinados a partir de la firma de los acuerdos, y para el año 2019 los asesinados fueron 77 (Organización de las Naciones Unidas [ONU], 2018; Guevara, 2019).

Los Espacios Territoriales de Capacitación y Reincorporación (ETCR) reemplazaron a las Zonas Veredales Transitorias de Normalización (ZVTN), y se afirma que hay 3.587 excombatientes en planes de formación en proyectos productivos, pero hay reportes indicadores apuntando a que en algunos de estos espacios las plantas eléctricas se dañan regularmente, además no existen plantas de tratamiento de aguas residuales, los niños no cuentan con escuelas cercanas y las que existen se inundan 
cuando llueve o están fuera de servicio. Así mismo, las noticias registran que desmovilizados abandonan las zonas de reincorporación por el abandono sufrido, la violencia y la COVID-19 (AFP, 2020).

Otro elemento que incide en la situación del campesinado es la posibilidad de mejoramiento de su calidad de vida a través de programas asociados a los Programas de Desarrollo con Enfoque Territorial (PDET). Como desarrollo normativo se expidió el Decreto 893 del 28 de mayo de 2017, el cual prioriza 16 PDET en 170 municipios del país, y aunque dichos programas deberían encontrarse armonizados con los Contratos Plan para la Paz y el Posconflicto (Contratos Paz) y los planes nacionales para la Reforma Rural Integral (RRI) -como lo indica el Conpes 3932 de 2018-, su avance tampoco es significativo.

En materia jurídica y política, se estima que cien normas del Acuerdo se han aprobado, pero aún quedan pendientes otras cien, entre las cuales falta por ratificar leyes de catastro, jurisdicción agraria, reforma a la ley orgánica de planeación, tratamiento diferencial para cultivadores de plantaciones de uso ilícito, las circunscripciones de paz, entre otras. Adicionalmente, según el debate de control político realizado, el desarrollo del Acuerdo de paz tiene un déficit de 1,3 billones de pesos para la atención de gastos asociados al posconflicto.

\section{Segunda reflexión: totalitarismo y polarización}

En esta parte es necesario definir dos fenómenos que han incidido en el pensamiento colectivo colombiano: totalitarismo y polarización. Cabe describir parte de la historia del conflicto interno colombiano, a fin de reflexionar acerca de las dificultades en la implementación de los acuerdos por falta de discernimiento de la población.

El clima social que se siente es propio de un Estado paralelo en el cual el Ejército, las fuerzas de inteligencia y de policía se confunden entre su función de mantener el orden público al combatir a las denominadas bandas criminales (Bacrim) y la protección hacia los reinsertados y sus líderes. Los discursos ideológicos extremistas ponen en medio a la fuerza pública y hacen que su labor siempre sea cuestionada. Esto pasa debido a la polarización política, como consecuencia de la radicalización de las posturas ideológicas que divergen entre sí, y que no permiten un punto de encuentro.
Según Cotler (1994), las bases de la democracia latinoamericana son débiles debido a la polarización, y esto se debe a la prolongada dominación y explotación por parte de los terratenientes y los capitalistas sobre los campesinos, indígenas y las poblaciones afrodescendientes. La polarización política justifica las acciones de los grupos criminales en pro de una ideología.

La polarización impregna todas las esferas, como por ejemplo los medios de comunicación, pues es notorio que existen noticieros a favor de determinadas ideologías, lo que parcializa la percepción del televidente común y la vuelve sectaria y fanática. El extremismo ideológico hace que el totalitarismo hacia las ideas de igualdad y equidad se manifieste con la indiferencia de las acciones que vulneran la democracia como principio. El discurso totalitarista político y las acciones de los grupos armados al margen de la ley hacia los campesinos, los reinsertados y los líderes sociales justifican las acciones de los más fuertes, porque ven en el débil una amenaza a sus intereses. Así se describe esta tendencia:

La ideología totalitaria invoca, desde luego, un principio "eterno" que pretende ser indistintamente el contenido último de la Naturaleza y el sentido irrevocable de la Historia: ley de la lucha de las razas humanas por la supervivencia y supremacía, en la versión nazi; ley del aplastamiento de las clases sociales moribundas por las emergentes, en la 'stalinista'. (Serrano, 2000, p. 96)

El totalitarismo como ideología tiene su origen en un individualismo extremo. Urdaneta (2008) lo describe como una manifestación absolutista de un hombre que revela su ambición y convence a otros para que lo apoyen; es el poder de una persona que representa a una sociedad, y para que no exista veneración a otra, se restringen las libertades. El totalitarismo siempre ha existido, el culto irracional hacia una figura representativa siempre se ha evidenciado, tanto en Oriente como en Occidente, en imperios, en dictaduras, en gobiernos de facto.

El totalitarismo es el absoluto del poder mediante la imposición del terror sistemático, no solo como recurso para dominar a los oponentes, sino como objetivo principal. Ni siquiera se contempla una discrepancia entre la conducta humana y la ley, porque el gobierno totalitario es la voz de la historia o de la conciencia del líder, y esa voz 
dirige y contiene las voluntades como ley natural. (Urdaneta, 2008, p. 15)

El término comenzó a estudiarse a partir del surgimiento del fascismo italiano, sin embargo, al establecer el contexto del significado, lo totalitario se refiere a toda ideología que no permite que otras personas con pensamientos diferentes alteren su interior. Lévinas (1977) considera que lo totalitario consiste en la posesión y la colonización del otro, en donde la subjetividad y la infinidad quedan atrapadas y el otro queda esclavizado.

No es necesario, empero, que exista un régimen de terror para hablar de totalitarismo. Colombia se muestra como una de las democracias más fuertes de Latinoamérica, y sin embargo es considerada una democracia imperfecta. Esto quiere decir que, aunque tenga elecciones libres y justas y se protejan libertades civiles, históricamente presenta fragilidad en la gobernabilidad y una cultura política subdesarrollada (Hola, 2015). En un estudio de la historia del conflicto armado en Colombia, Marquardt (2012) considera que la lucha campesina ha sido producto de cuatro dictaduras, de las cuales solo una fue notoria, y las describe así:

La primera dictadura la denominó civil, cuya tendencia fue el terrorismo ejercido por los presidentes Mariano Ospina Pérez, Laureano Gómez y Roberto Urdaneta, y abarcó desde 1948 hasta 1953 (desde esta época empezó el periodo conocido como La Violencia). La segunda fue militar, comprendió de 1953 a 1958 y paradójicamente ha sido la menos sangrienta. A la tercera la llamó dictadura de partido, que se consolidó con el Frente Nacional y duró de 1958 a 1974, en la cual el Partido Liberal y el Partido Conservador intercambiaron el poder. La cuarta fue la dictadura electoral, que el autor describe como una especie de totalitarismo donde la clase política les cerró las puertas de la competencia democrática a los partidos diferentes a los tradicionales. En esta última, las familias, las clases sociales, los terratenientes y la cultura gamonal establecieron mecanismos de defensa electoral y paramilitar para evitar que otros llegaran al poder.

En este punto es necesario afirmar que el gamonalismo sigue influenciando las esferas del poder en Colombia y se presenta como una de las fuerzas opositoras a los acuerdos de paz, y mantiene su fuerza gobernante en el campo colombiano mediante el uso de la violencia. Mondragón (2002) describe al gamonal como un capitalista burocrático que ha llegado al poder gracias a la colonización y la violencia ejercida sobre los habitantes del campo, no ha querido destruir al latifundista, al campesinado, a los indígenas o a las comunidades afrocolombianas, sino que los ha dividido, ha generado conflicto entre ellos para beneficiarse de la concentración violenta de la tierra. Los jefes de los partidos tradicionales son descritos por la historia como gamonales y la llegada del narcotráfico y el neoliberalismo ha favorecido la acumulación de su poder.

La Constitución de 1991 permitió que las diversas ideas en cabeza de sus representantes Ilegaran al poder. El clima democrático mejoró, aunque problemas como el narcotráfico, el terrorismo y el conflicto armado, entre otros, han tenido que resolverse por medio de programas como el Plan Colombia, la lucha frontal contra las bandas criminales o el Acuerdo de Paz entre el Gobierno Nacional y las Farc-EP. En los campos, el ambiente polarizador y totalitario se evidencia en el desolador panorama de la cultura de votar o elegir por el que diga un caudillo y generar un ambiente hostil frente a los que han dejado las armas y quieren involucrarse en la vida civil.

Asimismo, el exterminio de los campesinos y los líderes de izquierda por parte de los grupos paramilitares es un fenómeno que se ha presentado hace mucho más de dos años. En los 90 se realizó una comparación de cifras que se mostraban en los medios de comunicación y se transmitían en los informes hacia otros países frente a las cifras de un fenómeno que se pretendía esconder a finales de los años 80 y principios de los 90.

Según Giraldo (1994), organismos no gubernamentales de Colombia registraron 227 víctimas fatales entre mayo de 1989 y junio de1990 -periodo de mayor concentración de atentados terroristas atribuidos al narcotráfico, mientras en el mismo tiempo ocurrieron 2.969 asesinatos por móviles políticos, sin contar las muertes en combate. Esto representa un 7,69 \% con respecto a la violencia política. Entre enero de 1991 y mayo de 1992, las muertes violentas relacionadas con el narcotráfico representaron solo el 0,18 \% del total de muertes violentas ocurridas en Colombia. La confrontación armada entre Ejército y guerrilla produjo, entre 1988 y 1992, un total de 6.040 muertes violentas, incluyendo militares, guerrilleros y civiles alcanzados por el cruce de fuegos. Esta cifra corresponde al 
$4,7 \%$ del total de muertes violentas y al 30,5\% de las muertes violentas que tienen móviles políticos. Hay un $70 \%$ de estas últimas que demandan otra explicación.

Hay que decir que el asesinato de los campesinos y líderes sociales siempre ha quedado en el olvido, y esta indiferencia por parte del Estado está siendo aprovechada por los grupos armados disidentes que desean tomarse el control del territorio dejado por las Farc; quieren apoderarse de los terrenos y las rutas del narcotráfico, y los terratenientes desean volver a prácticas como la ganadería expansiva y la deforestación. Portodo esto, Giraldo (1994) describió la democracia colombiana como genocida, cuya característica es la impunidad, porque permite dejar intactas las estructuras y acaba la confianza en la administración de justicia, favoreciendo la justicia privada y sus diversas formas de violencia. Muestra de ello es que a principios de los años 90 la atención se centraba en la lucha contra el narcotráfico, mientras en los campos masacraban a los líderes políticos de la UP.

El contexto no ha cambiado, pues la democracia sigue siendo financiada por los gamonales, quienes con su discurso totalitario en torno a un líder o "salvador" obstaculizan el acceso a la justicia para los campesinos. La voluntad de oponerse a los acuerdos de paz, promover el rearme de las Fuerzas Militares con nuevas políticas de seguridad, buscar que el presidente objete la ley que promueve la Justicia Especial para la Paz (JEP), permanecer indiferente ante la muerte de los líderes sociales, etc., son actuaciones que desde el Legislativo polarizan los sectores y no permiten avances significativos para que los reinsertados y campesinos puedan gozar de un modelo de justicia diferente que les posibilite una redistribución de la tierra en la que ellos sean los principales beneficiados.

Ahora bien, la polarización, el totalitarismo ideológico y las propuestas de los gamonales de reformar las leyes que han buscado resarcir a las víctimas del conflicto son circunstancias que han traspasado fronteras y han hecho que la relatoría de la ONU recomiende medidas urgentes para detener el asesinato de los líderes sociales.

Los defensores de los derechos humanos están en peligro en la mayor parte del país y no se sienten seguros debido a los numerosos ataques, amenazas, la criminalización de su trabajo y la falta de acceso a la justicia. Su estigmatización en el discurso de los altos niveles del Estado los expone a mayores riesgos. Se enfrentan a campañas de difamación que buscan desacreditar su trabajo, asociándolos con la oposición política, acusándolos de tener nexos con paramilitares o llamándolos antipatriotas, criminales e incluso traidores. "También son estigmatizados por diversos sectores de la sociedad al Ilamarlos guerrilleros, informantes o personas antidesarrollo" (ONU, 2018, p. 2).

Han pasado más de tres años desde la firma del Acuerdo y los informes presentados por el Ministerio de Defensa de Colombia ante el debate de control político realizado por la representante a la Cámara Juanita Goebertus estiman que de 13.000 excombatientes que dejaron sus armas, 1.749 disidentes se han apartado de la firma de estos acuerdos y que en el $40 \%$ de los 170 municipios en los cuales se planea establecer programas de desarrollo territorial han incrementado el número de homicidios (Rangel \& Camargo, 2018). Las agresiones a los líderes sociales aumentaron $475 \%$, los asesinatos en un $143 \%$ en lo correspondiente al lapso 2017-2018. Para diciembre de 2018, 81 excombatientes y 21 familiares han sido asesinados a partir de la firma de los acuerdos.

Existen problemas en el marco jurídico para la implementación del Acuerdo y su ejecución. Uprimny, Marino, Restrepo y Saffon (2006) consideran que el debate acerca de cómo deben ser enfrentadas las masivas violaciones de los derechos humanos contiene elementos jurídicos, políticos y éticos que le otorgan cierto nivel de complejidad. El marco jurídico para la paz, por medio de una justicia transicional, desea transformar radicalmente el orden social y político de un país. La misión del Gobierno es equilibrar las exigencias de las víctimas del conflicto y lo pactado con los actores del conflicto, quienes condicionaron la entrega de las armas a unos presupuestos negociados.

Rojas y Muñoz (2018) afirman que la bipolaridad del Ejecutivo y la inseguridad jurídica en la implementación de los acuerdos de paz es un tema preocupante, pues ante la comunidad internacional se asegura su cumplimiento, pero en el diario trasegar político se actúa de manera distinta. Por ejemplo, en el trámite de la implementación de las curules de paz para las víctimas, el Gobierno Nacional no hizo el esfuerzo por salvar el quórum, lo cual hizo que se hundiera la iniciativa. 
A esto se suma la intención de recomendar la objeción de la JEP por parte de los detractores del Acuerdo, razón por la que el presidente Iván Duque se encontró en el dilema de sancionarla u objetarla; sin embargo, después de seis objeciones que elevaron los ánimos de la sociedad, la Corte Constitucional exhortó al mandatario a sancionar lo que hoy es la Ley 1657 de 2019.

Aunque la comunidad internacional ha apoyado a la JEP, sus opositores buscan la objeción por inconveniencia política y jurídica de la ley estatutaria que regula el funcionamiento de la justicia transicional como columna vertebral del Acuerdo. Las inconformidades pasan, entre otras, por el juzgamiento de los delitos sexuales hacia los menores por parte de la JEP. En el texto constitucional que la creó se estableció que debe conocer y juzgar cualquier delito sin distinciones si se encuentra relación con el conflicto armado.

Otra inconformidad está asociada al tema de la extradición: la Corte Constitucional, por medio de la Sentencia C-017 de 2018, fijó el funcionamiento de la JEP y dejó claro que no procederá la extradición para los guerrilleros que hayan cometidos delitos anteriores a la firma del Acuerdo, condicionándola a que el exguerrillero solicitado por otro Estado tenga la intención de contar la verdad en el sistema de justicia transicional.

Por lo tanto, en los dos puntos polémicos (delitos sexuales y extradición), el Alto Tribunal estipuló que no habrá altas condenas para no perjudicar la verdad, por lo que se deben aplicar sanciones alternativas y de menor cuantía para que no exista impunidad. Es así como las sanciones no se impondrán conforme a la naturaleza del delito, sino al grado de cumplimiento y al compromiso del excombatiente con el Sistema de Verdad, justicia, Reparación y No Repetición (SVJRNR).

\section{Tercera reflexión: la memoria, la Comisión de la Verdad y la justicia transicional-la memoria histórica a partir de la filosofía}

El objetivo en este punto se encuentra en la necesidad de discutir acerca de la importancia de la memoria histórica a partir de diferentes postulados filosóficos que podrán evidenciar el punto de partida para alcanzar la justicia requerida para lograr la paz.
La persistencia en la paz se ha tornado en un debate ideológico que ha retrasado la implementación de los acuerdos, lo cual se evidencia con las cifras anteriormente dadas. En primer lugar, la dificultad por aceptar que en Colombia existió conflicto armado pasa por matices políticos que no deben dejarse de lado. Para Abad (1989), desconocer que existió conflicto armado en Colombia se traduce en la imposibilidad de buscar una salida negociada a la guerra, donde los actores del conflicto serán vistos como simples delincuentes que deben someterse al Estado y ello impide cualquier negociación con un Ilamado enemigo.

De Gamboa (2005) considera que el reconocimiento del pasado en una sociedad es a la vez una obligación y un derecho, porque los regímenes represivos y la sociedad dominante pueden manipular el recuento de los hechos. Otro inconveniente para la memoria histórica es lo afirmado por Todorov (2003), para quien la memoria se deteriora en una sociedad extremadamente capitalista y consumista.

Al construir memoria se debe recurrir a determinadas fuentes y no solo a una, porque la historia siempre la cuentan los represores conforme a las interpretaciones hegemónicas, "No hay documento de cultura que no sea a la vez un documento de barbarie. Y así como este no está libre de barbarie, tampoco lo está el proceso de la transmisión a través del cual los unos lo heredan" (Benjamin, 2008, p. 6).

La ruta de la reconciliación exige que los grupos políticos de poder hagan de la Comisión de la Verdad un puente para el encuentro de lo realmente ocurrido, para que en efecto realice su trabajo de construir un relato común con el objetivo de quitarle ritmo a la violencia en determinados lugares del país, y más específicamente en el campo. Para Jelin (2002), existe una causa política referente al sentido de lo ocurrido, así como del sentido de la memoria, porque la memoria se encuentra inmersa en la causa política, lo que lleva a una lucha contra el olvido, es decir, se recuerda para no repetir.

Uprimny et al. (2006), por su parte, adujo que una justicia transicional basada en la amnesia tiende a fracasar en el contexto colombiano, y así lo predijo con la implementación de la Ley 975 de 2005 (Ley de Justicia y Paz). Por lo tanto, el modelo que consideró es el fundado en perdones "responsabilizantes", porque en este se respetan los principios democráticos y los derechos del Estado y las víctimas, 
para otorgar las garantías de no repetición; en este modelo la memoria juega un papel importante con componentes de justicia retributiva.

La función de la Comisión de la Verdad es participar en audiencias públicas de reconocimiento en las zonas donde las Farc ejercieron poder político y armado, con el fin de encontrar una sola verdad en la que se cuenten las violaciones a los derechos humanos, la responsabilidad colectiva de los actores del conflicto armado (Estado, guerrillas y paramilitares), el desplazamiento y despojo de tierras, el contexto histórico, el narcotráfico y su relación en todas las esferas, entre otros puntos.

Los inicios de esta comisión datan del año 1958, porque a partir de tal fecha comenzó el denominado Frente Nacional y se considera que ahí nació la insurgencia. Los fines de la Comisión de la Verdad se describen así:

El propósito general de las comisiones de la verdad es restaurar la dignidad de las víctimas y de las comunidades afectadas. Las comisiones buscan dar respuesta a sus necesidades, esperanzas, deseos, frustraciones, su sufrimiento y sus anhelos, luego de la terminación de la época generalizada de abusos. Las víctimas son la razón de ser de las comisiones de la verdad y sobre esta base se erigen la mayoría de los fines que, de manera directa o indirecta, se persiguen con las investigaciones, la elaboración del informe final y las recomendaciones. (Corte Constitucional, Sent. C-017/2018, p. 96)

La memoria histórica es fundamental para el reconocimiento de las atrocidades del pasado, es el único medio que permite establecer una narrativa común que sirva de punto de encuentro entre las ideologías divergentes. Cada actor narra su historia, hasta el punto que todos se consideran víctimas del conflicto armado colombiano, incluso los victimarios. Lo paradójico de este punto es que los principales detractores del Acuerdo, esto es, los militares de alto rango, se han sometido a la JEP y están gozando de sus beneficios, mientras que los gamonales se oponen. Una sola verdad satisface los intereses de las víctimas y contribuye al acceso a la justicia para los campesinos:

La justicia transicional trata de responder a este ideal a fin de que un pasado político cargado de vejaciones y perversiones pueda, con el tiempo, dar paso a una sociedad libre y equitativa, donde el recuerdo no produzca odio, ni terror, ni venganza. (De Gamboa, 2005, p. 33)

La desigualdad como producto de la injusticia es un fenómeno que se ha vendido históricamente como obra del azar; es decir que está dada por la naturaleza o por el destino. La difusión de la desigualdad en el campo colombiano como fenómeno normal por parte de los gamonales se refleja en la continua pobreza en la que se encuentran los habitantes del campo. Mate (2011) considera que los interesados en repetir el pasado no permiten el reencuentro con las injusticias para que las víctimas puedan establecer nuevos tiempos. El interés de los detractores de la justicia por medio de la memoria es que las víctimas queden relegadas en un estado que el tiempo deja en igualdad de condiciones de pobreza y vulnerabilidad, denominado por Benjamin (2008) como continuum; es decir, no existe forma de que el campesino pueda cambiar su fatal destino.

La justicia basada en la memoria consiste en considerar a quienes la historia ha querido esconder. Según Mate (2011):

La memoria se sitúa exactamente en ese punto de la historia en el que algo impensable para los cánones convencionales del conocimiento ocurre y en vez de dejarlo ir por el sumidero de la historia, es rescatado por una categoría que lo eleva a la condición de lo que merece ser pensado, de lo que da que pensar. Esa es la memoria. (p. 468)

De igual manera, Ricoeur (2000) estima pertinente entender la historia a partir de una representación del pasado en el que se refutan los argumentos de los historiadores tradicionales, con el firme propósito de comprender la realidad por medio de la generalidad.

Benjamin (2003), por su lado, planteó la metáfora del ángel de la historia, y lo representó como aquel que va hacia adelante, se resiste a devolverse, pero su cuerpo está orientado hacia atrás; la fuerza que empuja al ángel la denomina sturm o progreso. Así, la fuerza del progreso llega a configurarse como un distractor de la realidad de la violencia que no permite ver lo desolador de sus consecuencias; la historia así lo ha registrado con las vidas que fueron sacrificadas por regímenes totalitaristas en aras del avance. El capitalismo radical muestra el progreso 
como una esperanza que lleva a que la imaginación y la fantasía olviden la sangre de las generaciones que pagaron un precio alto como víctimas. El futuro que vislumbra el neoliberalismo hace que las fantasías olviden la sangre que el progreso ha derramado, y a ese distractor se le denomina consumismo.

Gandler (2011) afirma que la memoria se deja corromper fácilmente por aspectos económicos y sociales. Por ejemplo, en los procesos electorales, entre mejor esté la economía, a las personas menos les importará la verdad del pasado y el precio que han pagado las víctimas. Existe una pequeña grieta denominada tiempo a la que solo tienen acceso quienes no han cerrado los ojos frente al horror del pasado, que al contemplarlo se vuelve eternidad, se convierte en libertad y le permite a la memoria recobrar vida y emerger del olvido (Gandler, 2011):

No solamente los crímenes de los nacionalsocialistas están condenados al olvido, sino también los actos de resistencia, sobre todo cuando fueron realizados por judíos. Los nacionalsocialistas hicieron todo lo posible para que no quedara ningún recuerdo de la insurrección exitosa en el campo de exterminio Sobibor el 14 de octubre de 1943 a las 16 horas, en la cual lograron escapar 300 personas. Por esto se supo solo años después algo más de esta insurrección. Los poderosos siempre temen, no solamente el recuerdo de sus actos destructivos, sino también el recuerdo de la posibilidad de que personas mucho menos armadas y bajo el más estricto control posible puedan lograr rebelarse y matar a sus vigilantes. Si el recuerdo de estos dos aspectos clave de toda la historia humana, estuvieran más presentes en nuestras mentes, la sociedad represiva y explotadora no encontraría siquiera tiempo para despedirse. (Gandler, 2011, p. 100)

En este sentido, el estado continuum del campesino o del reinsertado de las Farc les impide representarse un futuro sin opresión, sin discriminación, sin manipulación, sin sangre, sin expropiación de tierras, sin desplazamiento, sin injusticia. A las víctimas les resulta imposible creer, porque su pasado ha sido la continua historia de la opresión por parte de los capataces, quienes no desean mirar hacia atrás y reconocer un conflicto del cual ellos han sido los principales causantes. La justicia se construye por medio de la memoria histórica contada por víctimas y reconocida por victimarios, para que el futuro como medida de tiempo se represente como una justicia que se espera a partir de acciones políticas reales en favor de los oprimidos y los aniquilados de siempre.

Al respecto, Benjamin (2008) propuso hacer de la memoria una teoría del conocimiento del pasado que va más allá del historicismo y las filosofías de la historia que tratan el fenómeno del tiempo como inagotable e imparable. Ello se entiende porque para el historicismo, el objeto de la historia es conocer las cosas tal cual son y tal cual han sido, pues pone los ojos únicamente sobre los hechos; es decir, se trata de un conocimiento científico de lo que ha pasado, pero no ante lo que no ha sido (lo derrotado y abandonado que quedan abandonados y subordinados ante los hechos). Ante esta teoría historicista se eleva el concepto de memoria, para el cual la realidad son los hechos y los que no se consideran hechos por los victimarios.

Ahora bien, Benjamin (2008) estableció un concepto más elaborado acerca del objeto de la memoria: el deber de memoria, ante el cual debe existir, por un lado, una especie de complicidad entre memoria y futuro $y$, por el otro, un nexo entre memoria $y$ conocimiento. "Con la memoria se puede construir el futuro y además conocer mejor la realidad. Hay, empero, algo más: el deber de memoria. La memoria como deber" (Mate, 2011, p. 471). Por lo tanto, la construcción de una verdadera democracia hacia futuro con fundamento en una realidad presente es establecer que la memoria debe considerarse como una ley para todos y que el nunca más supla cualquier intento de desviar la atención por medio de políticas económicas que les impide a las víctimas ver un futuro razonable. Mate (2011) lo explica con esta cita: "Hitler ha impuesto a los seres humanos en su estado de ausencia de libertad un nuevo imperativo categórico: orientar su pensamiento y su acción de modo que Auschwitz no se repita, que no vuelva a ocurrir nada semejante" (Adorno, 1966, p. 356).

La misión de la Comisión de la Verdad es establecer los hechos y los no-hechos para que la ciudadanía reconozca a las víctimas y revise quiénes han sido los causantes del conflicto armado colombiano. El fin de una justicia transicional es responsabilizar a los victimarios de sus actos, empero, también debe buscar recuperarlos para que exista un proceso de reconciliación con sus víctimas. La recuperación de la víctima se da por medio del reconocimiento político que pide cualquier tipo de proceso de paz 
por medio de curules y participación; además, el perdón como sentimiento colectivo se logra con el reconocimiento del daño causado a campesinos inocentes y la voluntad de las víctimas de enfrentarse a un pasado doloroso.

En este aspecto, Serra Vásquez (2003) considera que la participación política es una actividad práctica y reflexiva que permite la transformación social por medio del desarrollo de la identidad y la gestión de la sociedad en un entorno. En el marco del posconflicto, y en primera instancia, la tarea le corresponde a la Comisión de la Verdad, que comenzó su gestión el 28 de noviembre de 2018; el propósito de este grupo de expertos es erradicar la polarización y la repetición por medio de un proceso social y político para alcanzar un relato común. La primera tarea es concentrarse en los sitios donde existió mayor violencia, que son aquellos en los que todavía opera la ley del silencio y el riesgo de revivir el conflicto.

\section{CONCLUSIONES}

No se puede desconocer que la inmanencia o trascendencia del orden social justo comporta la vida social que se desarrolla conforme a las leyes. Este llega a ser un debitum social, que se genera por la relación en comunidad. "El orden justo, o armonía de la sociedad, aparece cuando se da a cada uno lo suyo". (Hervada, 1989, 186-187). El orden social es, pues, un logro que el Estado colombiano debe intentar como está descrito en la Ley 1448 de 2011 (Ley de Víctimas y Restitución de Tierras). Ver la cuestión relativa a la repartición de tierras en lo que impacta a la población, vulnerada por el conflicto, se constituye en un paso en la dirección adecuada, ya que permite contar con información real sobre el vasto tema de tierras y sobre los problemas derivados con el despojo durante décadas, en especial frente al campesinado, contribuyendo así con una necesidad propia en la formulación de políticas públicas encaminadas a la satisfacción de intereses de una sociedad con múltiples carencias, pero concretizada en un sector identificable.

Es básico entender que la primacía del problema social deriva en que el desarrollo de la sociedad colombiana se vea mermado, e incluso sea retrógrado. Es así que, en cuanto a reforma agraria, por ejemplo y a pesar de que Colombia cuenta con tierra disponible para los campesinos y para que la agricultura crezca, se debe tener en cuenta que hay una enorme desigualdad económica y social, la cual abarca la existencia de una desigual forma de discriminación de los menos favorecidos, que se recrudece aún más por la corrupción.

Esa inequidad, asociada a la pobreza y que en el campo deja ver grandes latifundios en manos de pocas personas, uno ha podido superarse y ha impedido el bienestar de la mayoría de la población.

De otra parte, la memoria como factor de justicia permite reconocer que es necesario un proceso de reconciliación nacional que involucre a los detractores del Acuerdo para identificar los factores que obstaculizan la paz en los campos de Colombia. La víctima y el victimario deben acercarse, la primera para recordar los hechos en un proceso de perdón que dignifique su estado, y el segundo para reconocer los hechos a partir del relato de la verdad y de ese modo garantizar la no repetición. La justicia se alcanza por medio de la memoria, que sirve de instrumento de acceso a la igualdad y a una paz duradera.

La reflexión evidenció que los factores que impiden elaborar un marco de justicia en el proceso de recordación, olvido y reconocimiento de las acciones criminales pasadas están asociados a la polarización política como consecuencia del totalitarismo ideológico a cargo de los gamonales, lo cual motiva la aparición de grupos criminales que asesinan a los líderes sociales para tomar posesión de las zonas dejadas por las Farc-EP.

Estos factores coartan el conocimiento de la verdad histórica del conflicto armado en Colombia, retrasan los procesos avalados por la Corte Constitucional y la comunidad internacional y obstaculizan la puesta en marcha de una reforma agraria, ahondando aún más en las contradicciones y extremos que caracterizan un pensamiento colectivo nacional que quiere justicia pero que no siempre la siembra. Así mismo, entorpecen la confianza denle el proceso de paz actual, porque a diario se presentan muertes de líderes sociales y el clima que se vive es de total impunidad. En ese sentido, el futuro no es alentador para quienes se someten a la justicia de transición.

La implementación de la justicia transicional como garantía de paz en Colombia podrá llevarse a cabo siempre y cuando se entienda la importancia de una sola verdad histórica producto de la memoria como teoría del conocimiento. Así las partes, la ciudadanía y los miembros de los partidos políticos podrán 
establecer puntos en común que permitan acceso a la justicia y a la participación democrática de los campesinos, los líderes sociales y los reinsertados. Por eso, no es viable hacer reformas a la Ley 1448 de 2011, en tanto aquellas pretenden perjudicar a los campesinos que han sido víctimas de despojos por parte de usurpadores que los han desplazado violentamente de sus tierras.

De igual manera, no deben existir reformas a la Justicia Especial para la Paz (JEP), pues actualmente hay serias dificultades para la implementación de la ley que da vía a las dificultades logísticas, políticas y de justicia presentadas en los Espacios Territoriales de Capacitación y Reincorporación (ETCR) que reemplazaron a las Zonas Veredales Transitorias de Normalización (ZVTN).

Aquí también se han descrito las dificultades jurídicas para la puesta en marcha de la JEP y el marco jurídico para la implementación del Acuerdo, que pasan de la discusión jurídica y filosófica al plano político y electoral. Por lo tanto, la tarea de la Comisión de la Verdad es contribuir a que en los sectores se reconozcan los hechos generadores del conflicto armado en Colombia, que las víctimas puedan encontrarse con su pasado por medio de procesos de reconciliación hacia los victimarios, y que estos puedan reconocer los hechos cometidos para que juntos lleguen a una verdad histórica.

El proceso de construcción de la memoria colectiva se realiza con el firme propósito de establecer su importancia en la reconstrucción de la verdadera historia, para que, una vez sea descubierta, contada y aceptada, permita el acceso a la justicia para las víctimas del conflicto armado.

Los obstáculos se presentan en la descripción de la afectación de la garantía de la participación democrática para los reinsertados y los campesinos, la vulneración de sus derechos y las muertes sistemáticas de los líderes sociales, que se han incrementado en el segundo semestre de 2019 e inicios de 2020, así como en las dificultades para su participación política y la polarización política. Este escenario es aprovechado por los grupos armados para apoderarse del terreno dejado por las Farc-EP e incrementar prácticas como la deforestación salvaje, las nuevas rutas del narcotráfico, la ganadería expansiva como la ocurrida en los años 60 y el creciente cultivo de plantaciones de uso ilícito.

Las críticas se dirigen a tener como inconveniente la JEP frente a la política criminal del Estado, lo que termina siendo una afrenta a las obligaciones internacionales adquiridas por Colombia.

Otro reto para el Estado es asegurar la participación política de los reinsertados de las Farc-EP como fuerza política, que aunque ya tienen su propio partido, su labor se ha visto boicoteada por sectores de ultraderecha. La participación política de un grupo implica la superación del abandono para convertirse en un actor que pretende impulsar un cambio social a quienes representa, que en este caso son los miembros de su partido y, según su objeto social, es la representación de la lucha del campesinado colombiano.

Se entiende, entonces, que aspectos como la imposibilidad de participación en escenarios democráticos de elección popular, la creciente polarización política entre izquierda y derecha aupada por partidos políticos anquilosados en este siglo en el poder, unido a la no implementación de los acuerdos, genera toda suerte de inconvenientes para una democracia que teóricamente se precia de ser participativa. Es claro que cualquier proceso de justicia de transición tiene diversas etapas, frente a lo cual se señala:

Un proceso de negociación y un acuerdo de paz tienen un alcance limitado. Permiten un primer paso fundamental e indispensable para la paz: el silenciamiento de los fusiles de los actores armados, pero no necesariamente eliminar los gérmenes de violencia y las raíces de la conflictividad. (Barreto, 2017, p. 165)

De cualquier modo, hay que reconocer que la perseverancia del Gobierno de Juan Manuel Santos y de las Farc-EP como firmantes permitió avances al menos en términos de no repetición, ya que este grupo ha cumplido con lo acordado y aquel gobierno hizo lo que pudo en aras de la implementación de los acuerdos. 


\section{REFERENCIAS}

Abad, I. (1989). La democracia y el tratamiento del enemigo interior. Análisis Político, 6, 48-66.

Adorno, T. (1966). Negative Dialektik. Suhrkamp. Madrid: Taurus.

AFP. (31 de enero de 2020). Exguerrilleros abandonan masivamente zona de reincorpración por violencia en Colombia. France 24. Recuperado de https://www.france24. com/es/20200131-exguerrilleros-abandonanmasivamente-zona-de-reincorpración-porviolencia-en-colombia

Barreto, M. (2017). Thinking peace and reconciliation in Colombia based on the peruvian experience: lessons through analysis of the commission on truth and reconciliation. Análisis Político, 30(90), 154-174.

Benjamin, W. (2003). La obra de arte en la época de su reproductibilidad técnica (Trad. A. E. Weikert). México D. F.: Itaca.

Benjamin, W. (2008). Tesis sobre la historia y otros fragmentos (Trad. B. Echeverría). México D. F.: Universidad Autónoma de la Ciudad de México-Itaca.

Consejo Nacional de Política Económica y Social. (2018). Conpes 3932, Lineamientos para la articulación del plan marco de implementación del Acuerdo Final con los instrumentos de planeación, programación y seguimiento a políticas públicas del orden nacional y territorial en línea. Recuperado el 20 de mayo de 2020 de https:/colaboracion.dnp.gov.co/ CDT/Conpes/Econ\%C3\%B3micos/3932.pdf

Corte Constitucional. Sala Plena. Sentencia C-017 de 2018. (M. P. Diana Fajardo Rivera, 21 de marzo de 2018).

Cotler, J. (1994). Política y sociedad en el Perú: cambios y continuidades. Lima: Instituto de Estudios Peruanos.
Das, V. (1997). Language and Body: Transactions in the Construction of Pain. Daedalus, 125(1), pp. 67-91.

De Gamboa, T. (2005). Justicia transicional: dilemas y remedios para lidiar con el pasado. Estudios Socio-Jurídicos, 7(1), 21-42.

Departamento Nacional de Planeación (DNP). (2017). Plan marco de implementación del Acuerdo Final para la Terminación del Conflicto y la Construcción de una Paz Estable y Duradera. Recuperado el 23 de marzo de 2020 de https://colaboracion.dnp.gov. co/CDT/Conpes/Econ\%C3\%B3micos/3932 Anexo\%20B_Plan\%20Marco\%20de\%20 Implementaci\%C3\%B3n\%20(PMI).pdf

Gandler, S. (2011). Para un concepto de no lineal de Historia. Reflexiones a partir de Walter Benjamin. Estudos e Pesquisas em Psicologia, 11(1), 56-102.

Giraldo, J. (1994). Colombia, esta democracia genocida. Medellín: Cristianisme i Justícia.

Gómez Gallero, J. J., García, J. E., Arango, A. L. \& Medrano Benavides, J. L. (2020). Apuntes retrospectivos sobre lo pactado entre el Gobierno colombiano y las Farc-EP: el acuerdo de paz colombiano tres años después. Utopía y Praxis Latinoamericana, 25(4), 264-282. Recuperado de https://www.redalyc.org/ journal/279/27963704020/html/

Gonzáles Suárez, A. M. (Ed.) \& Estrada Álvarez, J. (Coord.). (2019). El Acuerdo de paz en Colombia: entre la perfidia y la potencia transformadoraCiudad Autónoma de Buenos Aires: CLACSO; Bogotá: Gentes del Común-Centro de Pensamiento y Diálogo Político (CEPDIPO). Recuperado de http://biblioteca.clacso.edu. $\mathrm{ar} / \mathrm{gsdl} / \mathrm{collect} / \mathrm{clacso} /$ index/assoc/D14724. dir/El_acuerdo_de_paz_en_Colombia.pdf

Guevara, M. (31 de diciembre de 2019). 2019, el año más violento para los excombatientes 
de las Farc en Colombia. Noticias ONU. Recuperado de https://news.un.org/es/ story/2019/12/1467341

Hervada, J. (1989). Inmanencia y trascendencia en el derecho. Persona y Derecho, 21, 185-203.

Hola Chamy, C. (20 de enero de 2015). ¿Qué países de América Latina son los más y los menos democráticos? BBC News Mundo. Recuperado de https://www.bbc.com/mundo/ noticias/2015/01/150119_democracia_indice_economist_latinoamerica_ch

Instituto Kroc de Estudios Internacionales de Paz. (2017). Informe sobre el estado efectivo de implementación del acuerdo de paz en Colombia. Recuperado el 23 de marzo de 2020 de https://kroc.nd.edu/assets/257593/ informe_kroc.pdf

Jaramillo, P. (2006). Pobreza rural en Colombia. Revista Colombiana de Sociología, 27, 47-62.

Jelin, E. (2002). Los trabajos de la memoria. Madrid: Siglo XXI.

Lévinas, E. (1977). Totalidad e infinito: ensayo sobre la exterioridad. Salamanca: Sígueme.

Marquardt, B. (2012). Constitucionalismo científico. Dinámicas globales y locales. Bogotá: Temis.

Mate, R. (2011). Tratado de la injusticia. XX Conferencias Aranguren. Isegoría, 45, 445-487.

Meltzer, J. (2004). Justicia transicional y reconciliación en Colombia luego del conflicto armado: consideraciones para una posible cooperación canadiense. Bogotá: Focal.

Mondragón, H. (2002). La organización campesina en un ambiente de terror. Bogotá: Pontificia Universidade Católica de Sao Paulo. Recuperado el 7 de julio de 2021 de https://www. researchgate.net/publication/268275403 La_Organizacion_Campesina_en_un_Ambiente_de_Terror

Organización de las Naciones Unidas (ONU). (3 de diciembre de 2018). Colombia debe actuar para detener los asesinatos y ataques contra defensores y defensoras de los derechos humanos-Relator de la ONU. Recuperado el 23 de marzo de 2020 de http://www.hchr. org.co/files/comunicados/2018/comunicadoRelator-Defensores(2).pdf

Rangel, P. \& Camargo, K. (2018). Dos años de la firma del proceso de paz: entre la esperanza y el escepticismo. Bogotá: Universidad del Rosario

Rendón, J. (2003). Una comisión de la verdad en la encrucijada colombiana. Estudios Políticos, 23, 29-51.

Ricoeur, P. (2000). La memoria, la historia, el olvido. Madrid: Trotta.

Rojas, D., \& Muñoz, A. (2018). Inseguridad jurídica ante el impedimento del ejercicio de la acción pública de inconstitucionalidad dentro del proceso especial para la paz. lusta, 1(48), 199-225.

Ruiz González, L. E. (2020). Élites y restricciones institucionales de las reformas agrarias: la implementación del acuerdo de paz en Colombia. Revista de Derecho, 53, 87-109. Recuperado el 7 de julio de 2021 de https://rcientificas. uninorte.edu.co/index.php/derecho/article/ view/11941/214421444910

Semana Rural. (26 de noviembre de 2018). Dos años después: ¿cómo va el acuerdo de paz en la Colombia rural? Recuperado el 7 de julio de 2018 de https://semanarural.com/web/ articulo/acuerdo-de-paz-farc-gobierno-dosanos/713

Serra, L. (2003). Participación ciudadana y movimientos sociales. Encuentro, 64, 18-37.

Serrano de Haro, A. (2000). Totalitarismo y filosofía. Isegoría, 23, 91-115.

Todorov, T. (2003). Hope and Memory, Lessons from the Twentieth Century (Trad. D. Bellos). Princeton: Princeton University Press. 
Torres, H. (2010). El concepto de terrorismo de Estado. Una propuesta de Lege Ferenda. Diálogos de Saberes, 33, 129-147.

Uprimny, R., Marino, B., Restrepo, E. \& Saffon, M. (2006). ¿Justicia transicional sin transición? Reflexiones sobre verdad, justicia y reparación en Colombia. Bogotá: Dejusticia.

Urdaneta, A. (2008). El surgimiento del totalitarismo (siglos XIX y XX). Democracia siglo XXI [blog]. Recuperado el 16 de abril de 2020 de https://teodulolopezmelendez.wordpress. com/2008/10/01/el-surgimiento-del-totalitarismo-siglos-xix-y-xx/

\section{Leyes}

Ley 1448 de 2011). Por la cual se dictan medidas de atención, asistencia y reparación integral a las víctimas del conflicto armado interno y se dictan otras disposiciones. 10 de junio de 2011. D. O.: 48.096. 